\title{
Tamamı içeride ön çapraz bağ rekonstrüksiyonu
}

\section{All-inside $\mathrm{ACL}$ reconstruction}

\author{
Ertuğrul Akşahin ${ }^{1}$, İsmail Karasoy² \\ ${ }^{1}$ Ankara Medikal Park Hastanesi, Ortopedi ve Travmatoloji Servisi, Ankara, Türkiye \\ ${ }^{2}$ Gümüşhane Devlet Hastanesi, Ortopedi ve Travmatoloji Servisi, Gümüşhane, Türkiye
}

Tamamı içeride ön çapraz bağ (ÖÇB) rekonstrüksiyonu ortopedik rutinde yerini yeni yeni almaktadır. Tamamı içeride ÖÇB rekonstrüksiyonunda temel amaç cerrahi travmayı en asgari seviyeye indirmektir. Evrimsel süreci klasik ÖÇB rekonstrüksiyona benzemekle birlikte teknikler değiştikçe iki temel kavram sabit kalmaktadır: Soketlerin ya da yarı tünellerin hem femurda hem de tibiada içeriden dışarıya doğru açılması ve greftin artoskopik portallerden yerleştirilmesi. Tamamı içeride ÖÇB rekonstrüksiyonu ile klasik ÖÇB rekonstrüksiyonu yapılan hastalar karşılaştırıldığında ameliyat sonrası ağrının tamamı içeride grubunda daha az olduğu görülmüştür. Cerrahinin tünel yerine soket kullanılarak gerçekleştirilmesi kemik rezervinin korunmasını sağlayarak, çift demet ÖÇB ve/veya arka çapraz bağ (AÇB) cerrahileri, çoklu bağ yaralanması rekonstrüksiyonları, revizyon ÖÇB cerrahileri ve beraberinde yüksek tibial osteotomi cerrahileri gerektiren durumlarda cerraha avantaj sağlamaktadır. Tek tendon otogrefti kullanımı çift tendon otogreft kullanılan olgulara göre donör saha morbiditesini azaltmakta ve diz kinematiğine olumlu etkileri olmaktadır. Bununla birlikte pediatrik olgularda özellikle tamamı içeride tamamı epifiziyel ÖÇB onarımı tatminkâr sonuçlar vermektedir. Her ne kadar tekniğin öğrenim eğrisinin uzunluğu bir dezavantaj olarak görülmekle birlikte, kinik tecrübeler cerrahinin morbiditesinin klasik ÖÇB rekonstrüksiyonu tekniklerine göre daha az olduğunu ortaya çıkarmıştır. Bu durum tamamı içeride ön çapraz bağ rekonstrüksiyonunu gelecek vaat eden bir teknik olduğunu göstermiştir. Hâlihazırda literatürde yeterince randomize kontrollü çalışma bulunmamaktadır. Gelecekte daha geniş serilerle yapılacak çalışmalar tamamı içeride ÖÇB rekonstrüksiyonun daha ayrıntılı anlaşımasını sağlayacaktır.

Anahtar sözcülkler: ön çapraz bağ; tamamı içeride ÖÇB rekonstrüksiyonu
All-inside ACL reconstruction is getting its position in orthopaedic surgery day by day. The main aim of all-inside $A C L$ reconstruction is minimizing the surgical trauma. Its evolutional progress looks similar to classic ACL reconstruction although two basic concept remained steady: sockets, or half-tunnels, are drilled from inside-out on both the femur and tibia and (2) the graft is introduced into the knee through an arthroscopic portal. When we compare all-inside and classic ACL reconstruction, patients postoperative pain is significantly lower in all-inside group. Performing the surgery by using sockets instead of tunnels provides adequate bone stock and it is an advantages to surgeon performing double bundle $A C L$ and/or $\mathrm{PCL}$ reconstruction, multi-ligament reconstruction surgeries, revision $A C L$ surgeries and in $A C L$ reconstruction cases accompanying high tibial osteotomies. Using single tendon decreases morbidity due to autograft usage and it has positive effects on knee kinematics with regard to double tendon usage. Additionally, in pediatric cases the results of All-inside all-epiphyseal $A C L$ reconstruction are satisfactory. Although long learning curve of this techniques seems to be a disadvantage, clinical experience revealed that it has less surgical morbidity with regard to classic $A C L$ reconstruction techniques. This makes allinside $A C L$ reconstruction as a promising concept but still in the literature there are not enough randomized controlled clinical trials. We think that in the future randomized controlled clinical trials with greater series will help us more detailed understanding of all-inside $A C L$ reconstruction.

Key words: anterior cruciate ligament; all-inside $\mathrm{ACL}$ reconstruction

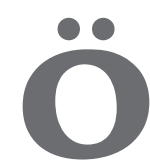

n çapraz bağ (ÖÇB) yaralanmaları ortopedik rutinde sık görülen bir yaralanma olup rekreasyonel/profesyonel sporların öneminin arttığı günümüzde, tedavisi bireyin/sporcunun gündelik hayata/spora dönüşü açısından önem arz etmektedir. Özellikle profesyonel spor dallarında hem sporcunun hem de kulüplerin sportif/maddi başarı beklentileri ortopedi ve travmatoloji uzmanları üzerinde ciddi bir baskı oluşturmaktadır. Bu nedenlerden dolayı hem cerrahlar hem de medikal endüstri hasta morbiditesini minimize eden, daha etkin ve komplikasyon oranı daha az teknikler geliştirmeye çalışmaktadır. "Tamamı içeride ÖÇB rekonstrüksiyonu" kavramı da bu sürecin sonuçlarından biridir.

- İletişim adresi: Prof. Dr. Ertuğrul Akşahin, Yüksek İhtisas Üniversitesi, Ankara Medikal Park Hastanesi, Batıkent, Ankara Tel: 0533 - 4820062 e-posta: ertugrul_aksahin@hotmail.com

- Geliș tarihi: 17 Nisan $2020 \quad$ Kabul tarihi: 9 Mayıs 2020 
Tamamı içeride ÖÇB rekonstrüksiyonunda temel amaç cerrahi travmayı en asgari seviyeye indirmektir. ${ }^{[1]}$ Standart ÖÇB rekonstrüksiyon tekniklerine göre daha yeni bir kavram olmakla birlikte; daha anatomik, daha az invaziv ve daha hızlı iyileşme süreci sağlamasından dolayı hızla popülerlik kazanmaktadır. ${ }^{[2]}$ Allogreft kullanıldığında "kesisiz" teknik olarak da adlandırılabilir. ${ }^{[3]}$ Ayrıca pediatrik ÖÇB yaralanmalarında tamamı içeride ÖÇB rekonstrüksiyonu tekniği ile tamamı içeride epifiziyel onarımlar yapılabilmektedir ve konuyla ilgili çalışmalarda sonuçlar yüz güldürücüdür. ${ }^{[4]}$ Bununla birlikte çoklu bağ yaralanmalarında kemik rezervini koruması avantajı nedeniyle tamamı içeride teknikle bikrusiyat (her iki çapraz) bağ rekonstrüksiyon teknikleri geliştirilmiştir. ${ }^{[5]}$

Bu yazımızda tamamı içerinde ÖÇB rekonstrüksiyonu tarihsel gelişiminden, avantajlarından, dezavantajlarından, kullanımda olan tekniklerden ve kendi klinik tecrübelerimizden bahsedeceğiz.

\section{TARIHÇESi}

Tamamı içerinde ÖÇB rekonstrüksiyonu ilk kez Morgan ve ark. tarafından 1995 yılında tanımlandı. ${ }^{[6]}$ Yazarlar tekniklerinde yüksek anteromedial portal kullanarak tibial soketi içeriden-dışarı yönde deldiklerini ve sonrasında da grefti aynı şekilde içeridendışarı yerleştirip interferans vidasıyla tespit ettiklerini belirttiler. Teknik olarak zor bir yöntemdi. 2006 yılında Lubowitz transtibial tamamı içerinde ÖÇB rekonstrüksiyonu tanımladı. Bu teknikte kanüle, artroskopik bir drill tipi olan Dual Retrocutter (Arthrex, Naples, FL) kullanarak hem antegrad yönde femoral tünel hem de retrograd yönde tibial soketler açılabiliyordu. Greft anteromedial portalden eklem içine yerleştirildikten sonra her iki tünele interferans vidaları ile tespit ediliyordu. ${ }^{[3]}$ Medikal teknolojideki bu gelişmeler bu cerrahinin gün geçtikçe evrimleşmesine neden oldu. Retrograd delmenin keşfi tama$\mathrm{m}$ içerinde ÖÇB rekonstrüksiyonunda yeni teknikler geliştirilmesine neden oldu. ${ }^{[7]}$ Cerulli ve ark., 2011 yılında kendi tabirleriyle "Asıl tamamı içeride teknik" dedikleri çalışmalarını yayımladılar. Bu teknikte retrograd drill kullanarak her iki tüneli birbirinden bağımsız şekilde içeriden-dışarı yönde açabiliyorlardı.. ${ }^{[1]}$ Yine Lubowitz ve ark., ikinci nesil Flipcutter (Arthrex, Naples, FL, USA) kullanarak yaptıkları anatomik, tek demet tamamı içerinde ÖÇB rekonstrüksiyonu greft-link tekniğini yayımladılar. ${ }^{[8]}$

Tamamı içeride ÖÇB rekonstrüksiyonu tanımlandığı günden bu güne kadar birçok değişik teknik tanımlanmakla birlikte temelde iki şey sabit kaldı: Tünellerin içeriden dışarıya açılması ve greftin portallerden yerleştirilmesi. ${ }^{[9]}$

\section{TEKNIĞiN AVANTAJLARI}

\section{Ameliyat Sonrası Ağrı}

Klasik ÖÇB rekonstrüksiyonu tekniğiyle karşılaştırıldığında ameliyat sonrası ağrının tamamı içeride ÖÇB rekonstrüksiyonu yapılan hastalarda daha az olduğu görülmüştür. ${ }^{[10,11]}$ Ameliyat sonrası ağrı azlığının nedenleri olarak; tibial cilt kesisinin olmaması ya da daha kısa olması, soketin dış kortekse ulaşmaması ve dolayısıyla periostal bütünlüğünün minimal hasar görmesi (sadece retrodrill çapı olan $4 \mathrm{~mm}$ çapında giriş deliği oluşur), tek bir hamstring tendonunun kullanılması nedeniyle dönor saha morbiditesinin azlığı sayılabilir. ${ }^{[10,11]}$

\section{Doğru Tünel Seçimi}

Tünellerin yerleşimi ÖÇB rekonstrüksiyonunun başarılı olabilmesi için çok önem arz etmektedir. Tamamı içeride ÖÇB rekonstrüksiyonunda retrograd oyma yapabilen drill Flipcutter (Arthrex, Naples, FL, USA) kullanılarak daha doğru ve anatomik bir tibial tünel (soket) yerleşimi elde edilebilmektedir. ${ }^{[12]}$ Tamamı içeride teknik doğru tünel seçimi anlamında özelikle femoral tünel açılımında klasik tekniğe göre daha avantajlıdır. Soket açılışında kullanılan femoral kılavuz anterolateral portalden yerleştirileceğinden, görüntüleme anteomedial portalden rahatlıkla yapılabilmektedir. Klasik yöntemin aksine, diz aşırı fleksiyona alınmaksızın $90^{\circ}$ fleksiyonda iken uygun görüntüleme sağlanabilmektedir (klasik teknikte aşırı diz fleksiyonu görüntüleme zorluğu yaratabilir). Dolayısıyla daha rahat teknikle, daha doğru tünel yerleşimi ile femoral tünel açılabilmesi sağlanmaktadır. ${ }^{[13]}$ Biz uygulamalarımızda sadece pediatrik olgularda femoral kılavuz kullanmaktayız. Erişkin olgularda femoral tünelin doğru anatomik lokalizasyonda açıldığından emin olmak için anteromedial portalden görüntüleme yapıyoruz.

\section{Kemik Stoğunun Korunması}

Tamamı içeride ÖÇB rekonstrüksiyonunda retrograd oyma yapabilen drill Flipcutter (Arthrex, Naples, FL, USA) kullanımı femoral ve tibial tünel ihtiyacını ortadan kaldırmış, tünellerin yerine daha kısa olan soketlerin kullanılmasını sağlamıştır. Bu durum klasik tekniğe göre kemik rezervinin korunabilmesini sağlamış olup özellikle çoklu bağ yaralanmalarının tedavisinde ve ÖÇB rekonstrüksiyonu revizyon cerrahileri düşünüldüğünde tekniğin önemli bir avantajıdır. Retrograd oyma işleminin antegrad oyma işlemine göre tibia proksimalinde patlama (blow-out) kırıklarının oluşması ihtimalini azalttığı gösterilmiştir. ${ }^{14]}$ Hem tibial korteksin korunması hem de yeterli kemik stoğunun olması nedeniyle tamamı içeride ÖÇB 

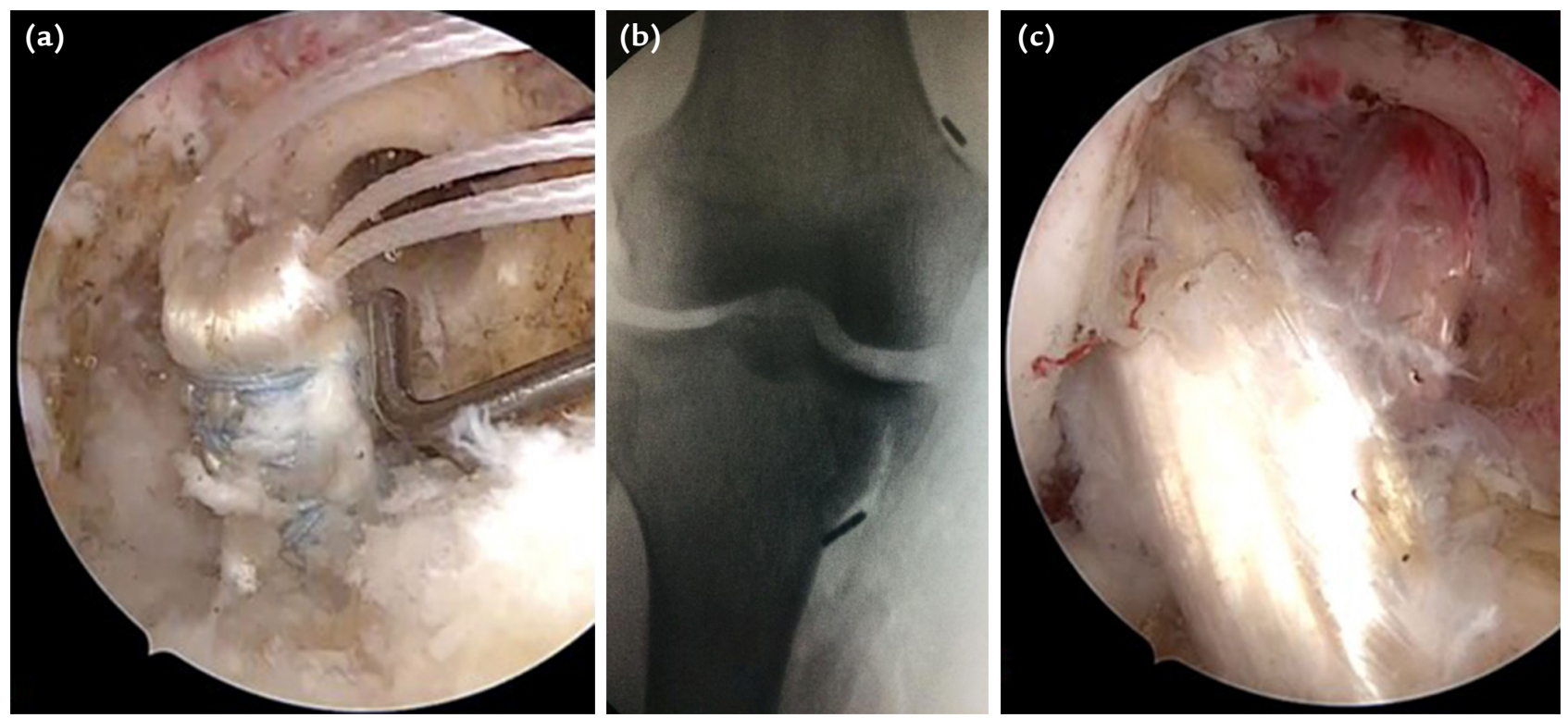

Şekil 1. a-c. Bikrusiyat (her iki çapraz bağ) yaralanması olan 44 yaşında kadın hastada arka çapraz bağın (AÇB) tamamı içeride yöntemle rekonstrüksiyonu sırasında tendonun soketlere çekilmesi işlemi (a). Hastanın AÇB rekosntrüksiyonu sonrası skopi görünümü (b). Her iki çapraz bağ rekonstrüksiyonu sonrası artroskopik görünüm (c).

rekonstrüksiyonu yüksek tibial osteotomi gibi başka cerrahi işlemlerle beraber ya da ACL-PCL eş zamanlı onarımlarında kullanılabilir (Şekil 1). ${ }^{[15]}$

\section{Greft Biyolojisi ve İntegrasyonu}

Tamamı içeride ÖÇB rekonstrüksiyonunun en gözle görünür avantajı proksimal medial tibial kesinin olmaması nedeniyle sağladığı kozmetik görünümdür. ${ }^{[8]}$

Tünellerin yerine soketlerin kullanımı greft biyolojisini etkileyecek sonuçlar da ortaya çıkarmaktadır. Soket uygulaması kullanılan greftin daha kısa olmasını ve greft tarafından doldurulmayan ölü alanın miktarının azaltmasını sağlamakta ve böylece greftin tünel içinde hem longitudinal yönde (bungee etkisi) hem de transvers yönde (windshield etkisi) hareketini azaltmaktadır. ${ }^{[12]}$ Connaughton ve ark., çalışmalarında soket kullanımının tünel genişlemesini azaltacak koruyucu etkisinin olabileceğini bildirmişlerdir. ${ }^{[16]}$ Ayrıca soket kullanımına bağlı kısa greft kullanımı bükülme direncinde artma, greft gerginliğinde ve greftin yıpranmasında azalmaya neden olacaktır. ${ }^{[3,12]}$

Tamamı içeride tekniğin tünel yerine soketler kullanılarak yapılması yukarıda belirttiğimiz biyomekanik ve biyolojik birtakım avantajlar getirse de bu teknikte hem femoral hem de tibial tarafta kullanılan ekstra-kortikal tespitlerin (greftin çalışma mesafesinin artması nedeniyle) greft elongasyonuna neden olduğu yönünde bir takım çalışmalar mevcuttur. ${ }^{[17,18]}$ Biyomekanik çalışmalar ve hayvan deneylerinin sonuçlarında genel kabul gören görüşlerden biri biyomekanik olarak en dayanıklı sistemin vida/düğme kombinasyonları olduğu bunu vida sistemlerinin ve sonrasında düğme sistemlerinin takip ettiğidir. ${ }^{[17,18]}$ Tespit sistemlerinin biyomekaniğinin klinik sonuçlarıyla ilgili bir meta-analizde, patellar bone tendon bone (PBTB) tespiti uygulamaları, tünel içi tespit yapılan hamstring tendon uygulamaları ve ekstrakortikal (suspensory) tespit yapılan hamstring tendon grefti uygulamaları karşılaştırılmış, greft yetmezliği ve diz laksitesinin restorasyonu açısından teknikler arasında fark bulunamamıştır. Ancak yaralanma öncesi aktivite düzeyine dönüş ve hasta tatmini açısından, PBTB tekniği ve tünel içi tespit yapılan hamstring tendon kullanılan grup benzer çıkarken, hamstring tendon greftinin ekstrakortikal tespitinin yapıldığı grup sonuçları daha kötü çıkmıştır. Ancak meta-analizde yer alan çalışmaların hiçbirinde tamamı içeride tekniğin kullanılmadığı görülmektedir. ${ }^{[19]}$ Öte yandan başka bir çalışmada Smith ve ark., soket içi kortikal-düğme askı tespit sistemleri ile tünel içi interferans vidası tespit sistemlerini karşılaştırdıkları hayvan çalışmalarında soket/askı grubunda greftin kemiğe daha iyi entegre olduğunu göstermişlerdir. ${ }^{[20]}$

Tamamı içeride teknikte kullanılan asansör askı sistemlerinin olası handikaplarından biri greft gerginliği sağlandıktan sonra askı sisteminin siklik hareketler ve 
yüklenmeler sonrası gevşeyebileceğidir. Bunu önlem amaçlı greft gerildikten sonra siklik diz hareketleri sonrasında greftin gerginliği tekrar kontrol edilmeli ve askı sistemi uygun pozisyonda tekrar gerilmelidir. ${ }^{[21]}$ Greft elongasyonun önlenmesi amaçlı askı sistemi uygulamasında alınacak diğer bir tedbir ise düğme üzerinde iplerin düğümlenmesidir. ${ }^{[22]}$

\section{Diz Kinematiği}

Tamamı içeride ÖÇB rekonstrüksiyonunda standart ÖÇB rekonstrüksiyonunda kullanılabilen tüm greftler (otogreft-allogreft) kullanılabilmekle birlikte en sık kullanılan greft üçlü ya da dörtlü sarmal haline getirilip yerleştirilen semitendinosus (ST) tendonudur. ${ }^{[2]}$ Soketlerin tünellere göre daha kısa olması nedeniyle tek bir hamstring tendonun kullanımı sıklıkla yeterli kılacaktır. Tek bir hamstring tendonun yeterli olması klasik ÖÇB rekonstrüksiyonunda kullanılan patellar BTB veya ikili semitendinosus-gracilis (STG) greftleri göz önüne alındığında daha az donör saha morbiditesine neden olmaktadır. ${ }^{[16]}$ Segawa ve ark., yaptıkları çalışmalarında, tek hamstring tendonun kullanılmasının hem morbiditeyi azalttığını hem de rezidü diz fleksiyon kuvvetini iyileştirdiğini göstermişlerdir. ${ }^{[23]}$ Yine Monaco ve ark., izokinetik fleksiyon güçlerini karşılaştırdıkları çalışmalarında, tek ST grefti kullanılan tek demet tamamı içeride ÖÇB rekonstrüksiyonu yapılan hastaların ST-G grefti kullanılan tam tibial tünel ile rekonstrüksiyon yapılan hastalara göre fleksiyon kuvvetinde düşük açısal vektörel hızda daha iyi iyileşme olduğunu göstermişlerdir. ${ }^{[24]}$

\section{TEKNIĞiN DEZAVANTAJLARI}

Tamamı içeride ÖÇB rekonstrüksiyonunun üzerinde durulan temel dezavantajı ise tamamı içeride ÖÇB rekonstrüksiyonu daha uzun bir öğrenim süreci gerektirdiği ve daha yetkin cerrahlar tarafından yapılması gerektiğidir. ${ }^{[15]}$ Özellikle anteromedial portal tekniğinde femoral soketin açılması teknik olarak cerrahları zorlamaktadır. ${ }^{[16]}$ Shurz ve ark., çalışmalarında tamamı içeride ÖÇB rekonstrüksiyonu hastalarında daha yüksek oranda greft yetmezliği geliştiğini ifade etmekle birlikte bunu femoral tünelin pozisyonu ve pivot sporlara erken dönüşe bağlamakla birlikte daha uzun süreli takip gerektiğini ifade etmektedirler. ${ }^{[13]}$ Ayrıca tamamı içeride ÖÇB rekonstrüksiyonun standart ÖÇB rekonstrüksiyonundan daha pahalı olduğuna dair çalışma mevcuttur. ${ }^{[25]}$

Çalışmanın yazarlarına göre tamamı içeride ÖÇB cerrahisinin diğer bir dezavantajı da özellikle tibial tünelin tam bir tünel değil de soket şeklinde olması cerrahi hematomun kısmen de olsa tibial tünelden drenajını etkilemekte ve bu nedenle tamamı içeride
ÖÇB rekonstrüksiyonu olgularında daha fazla ameliyat sonrası hematomla karşılaşılmaktadır. Bu sorunu önlemek amaçlı iki uçlu dren kullanılmaktayız ve dreni 48 saat sonra çekmekteyiz. Yine ameliyat sonrası 7. gün kontrolümüzde bazı olgularımızda diz içi hematom sorunuyla karşılaşmaktayız ve ponksiyon işlemi uygulamaktayız.

\section{Tek Demet Tamamı İçeride ÖÇB Cerrahisindeki Önemli Noktalar}

Gerek tek demet gerekse de çift demet tamamı içeride ÖÇB rekonstrüksiyonunun temel cerrahi püf noktalarından biri soket uzunluklarının doğru hesaplanmasıdır. Bu hesaplamalar tünel uzunluklarının ve greftin eklem içinde kalacak kısmının toplamının, greftin uzunluğunun yarım santim fazlası olacak şekilde yapılır. Uygun hesapla bırakılacak bu yarım santimlik fark greftin gerdirilebilmesi ve uygun gerilimin sağlanması için gereklidir. Ayrıca anteromedial portal greftin ekleme girişine izin vermesi için klasik anteromedial portale göre daha büyük açılmalıdır (8-10 mm). Biz klinik uygulamamızda anteromedial portali cerrahi sırasında aşırı sıvı kaçağına izin vermemek için cerrahinin başında klasik uzunlukta açmaktayız. Gerek greft hazırlığı gerekse de femoral-tibial soketler hazırlandıktan sonra grefti yerleştirmeden hemen önce portali bir miktar genişletmekteyiz.

Greft hazırlığı sırasında diz içi bir takım cerrahi ön hazırlıklar yapılmaktadır. Bunlardan birincisi greftin anteromedial portalden giriş sırasında olası takılma sorunlarıyla karşılaşmamak için anteromedial portal önündeki dokuların iyi temizlenmesidir. Bu özellikle tekniğe yeni başlayanlar için cerrahinin son aşamasında oluşabilecek beklenmedik sorunları önlemek açısından önemlidir. Diğer bir konu ÖÇB güdüğünün temizlenme meselesidir. Bu konuda bazı yazarlar Georgoulis ve ark.'nın görüşüne uygun olarak ÖÇB güdüğünün hala mekanoreseptör içerdiğini ve bu nedenle propriyoseptif duyuya katkısı olacağından korunmasını gerektiğini savunmaktadırlar. ${ }^{[26]} \mathrm{Bu}$ görüş bazı çalışmalarla desteklense de ${ }^{[27]}$ ÖÇB güdüğünün korunmasının kliniğe pozitif bir yansıması olmadığı görüşünde olan çalışmalarda mevcuttur. ${ }^{[28]}$ Yakın zamanda yayımlanmış bir gözden geçirme çalışmasında ÖÇB güdüğünün yaralanma sonrası altı aydan daha az geçmiş, kopmuş ÖÇB'nin arkasındaki arka çapraz bağa $(A C ̧ B)$ yapışmış ve dolayısıyla hala bir miktar tansiyonunu koruyan olgularda korunması gerektiği belirtilmiştir. ${ }^{[29]}$ Bizim görüşümüz, cevabı verilmesi gereken asıl sorunun ÖÇB yaralanması etyopatogenezinde propriyoseptif duyudaki bir takım handikapların olduğundan yola çıkarak, 'hâlihazırda potansiyel handikaplı mekanoreseptörlerin, kopmuş bir ÖÇB 

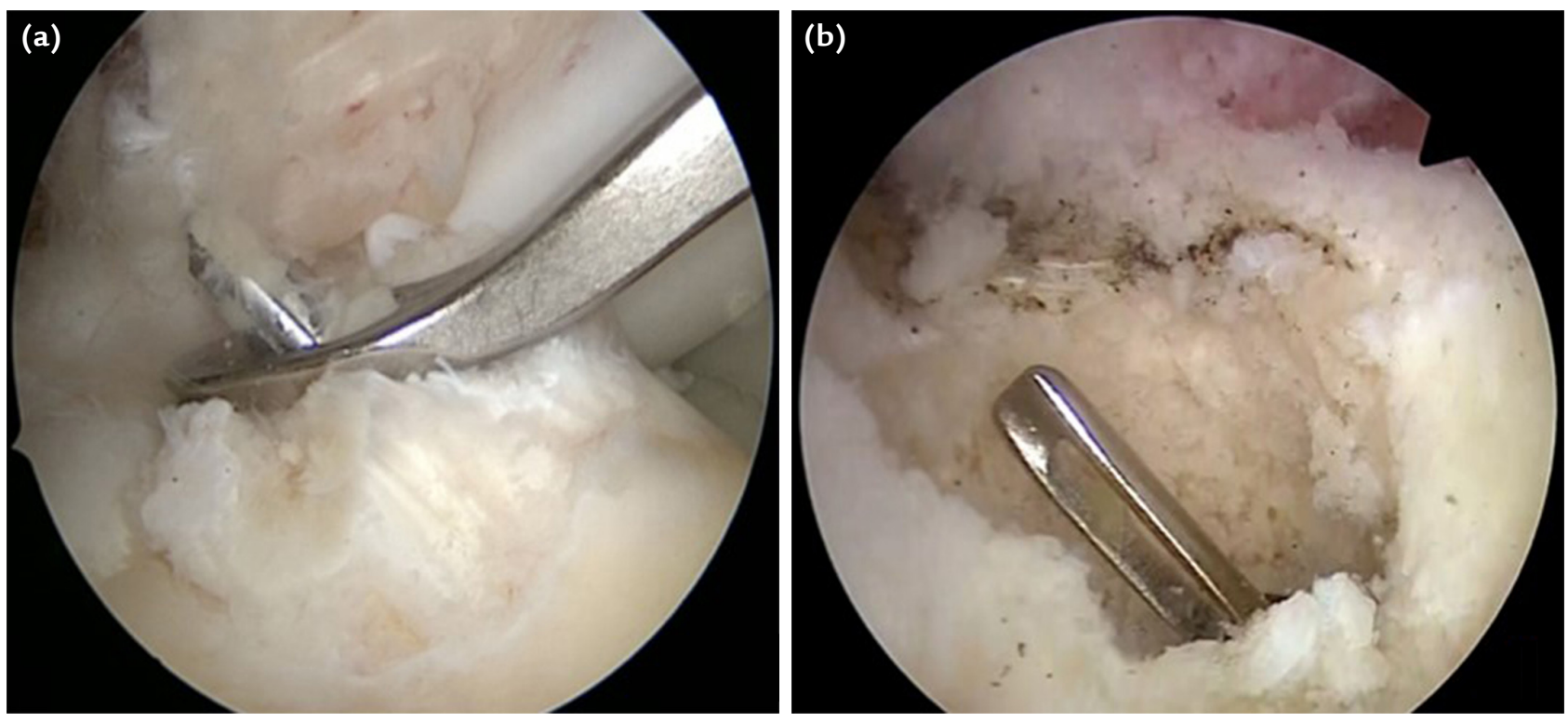

Şekil 2. a, b. Yaralanma sonrası 3. ayında olan olguda ÖÇB güdüğünün korunması (a). Yaralanma sonrası 2. yılında olan olguda ÖÇB güdüğünün tamamen temizlenmesi (b).

güdüğünde ne kadar fonksiyon görebileceği' sorusudur. Tamamı içeride ÖÇB cerrahisi özelinde düşünüldüğünde özellikle güdüğün temizlenmediği olgularda greftin sokete çekilmesi sırasında bir takım sorunlarla karşılaşılması bazen cerrahiyi zorlaştırmaktadır. Biz yaralanma sonrasında altı aydan fazla geçen tüm olgularımızda ÖÇB güdüğünü özellikle tama yakın temizliyoruz (Şekil 2).

\section{Çift Demet Tamamı İçeride Ön Çapraz Bağ Rekonstrüksiyonu}

Klasik ÖÇB rekonstrüksiyonun evrimsel sürecine benzer bir şekilde zaman ilerledikçe tamamı içeride ÖÇB rekonstrüksiyonu başlığı içerisinde çift demet tamamı içeride ÖÇB rekonstrüksiyonu kavramı ortaya çıkmıştır. Klasik çift demet ÖÇB rekonstrüksiyonu sırasında toplamda dört adet tünel açılması kemik rezervini ciddi ölçüde azaltmakta ayrıca antegrad delme yöntemi de proksimal tibiada mikro-kırık riskini artırmaktadır. Bu nedenlerden dolayı tamamı içeride ÖÇB rekonstrüksiyon tekniği çift demet ÖÇB rekonstrüksiyonu için bariz avantajlar ortaya çıkarmıştır.

Çift demet tamamı içeride ÖÇB rekonstrüksiyonu ilk kez Smith ve ark. tarafından tanımlanmıştır ve bu teknikte anteromedial portalden femoral soketler açılarak rekonstrüksiyon gerçekleştirilmiştir. ${ }^{[30]}$ Tsai ve ark., tek demet tamamı içeride ÖçB rekonstrüksiyonu ile çift demet tamamı içeride
ÖÇB rekonstrüksiyonunu karşılaştırdıkları biyomekanik çalışmalarında çift demet tamamı içeride ÖÇB rekonstrüksiyonunun rotasyonel diz stabilitesine katkısının daha fazla olduğunu göstermişlerdir.[31] Yasen ve ark., daha önce tanımladıkları translateral ÖÇB rekonstrüksiyonu tekniğini geliştirerek yaptıkları çalışmalarında iyi klinik sonuçlar bildirmiş̧lerdir. Bu teknikte tibial soket tek planlanmış olup, greft proksimal iki bacağı femoral soketlere, distal tek bacağı ise tibial sokete yerleştirilecek şekilde hazırlanmıştır. ${ }^{[32]}$ Watanabe ve ark., çalışmalarında çift demet tamamı içeride ÖÇB rekonstrüksiyonunu teknik olarak zor olduğunu belirtseler de onlar da iyi klinik sonuçlar bildirmişlerdir. ${ }^{[33]}$ Takashi ve ark., çalışmalarında daha önce yayımladıkları tekniklerini daha da modifiye ederek transtibial çift demet ÖÇB rekonstrüksiyonda soket girişlerinin daha kolay ve daha isabetli bir şekilde yapabildiklerini ifade etmektedirler. ${ }^{[34]}$

Çalışmanın yazarları çift demet ÖÇB rekonstrüksiyonunu uygulayacakları hastalarda Yasen ve ark.'nın 'TriLink' olarak isimlendirdiği üzere tek tibial ve çift femoral soketten oluşan tamamı içeride ÖÇB rekonstrüksiyonu uygulamaktadır. ${ }^{[32]}$ Özellikle rotasyonel stabilitenin de üst düzeyde sağlanması gereken yarışmacı spor yapan amatör sporcularda ve tüm profesyonel sporcularda bu tekniği kullanmaktayız. Diğer hasta gruplarında tek bant ÖÇB rekonstrüksiyonunu tercih ediyoruz. 

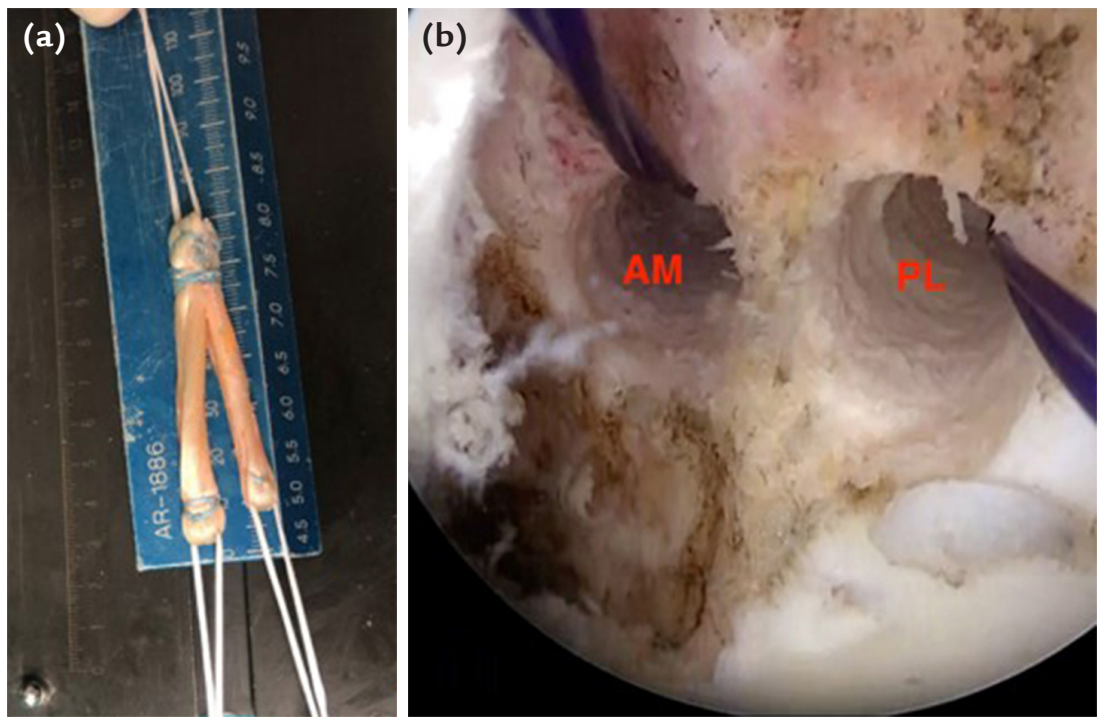

Şekil 3. a-d. Tek tibial çift femoral demet ÖÇB greftin hazırlığı (a). Bir başka hastada $A M$ ve $P L$ tüneller açıldıktan ve taşıma sütürler iyerleştirildikten sonraki görünüm (b). Çift demet ÖÇB uygulaması sonrasında AM ve PL demet gerginliklerinin prob yardımıyla kontrolü (c). Hastanın ameliyat sonrası direkt radyografisi (d).
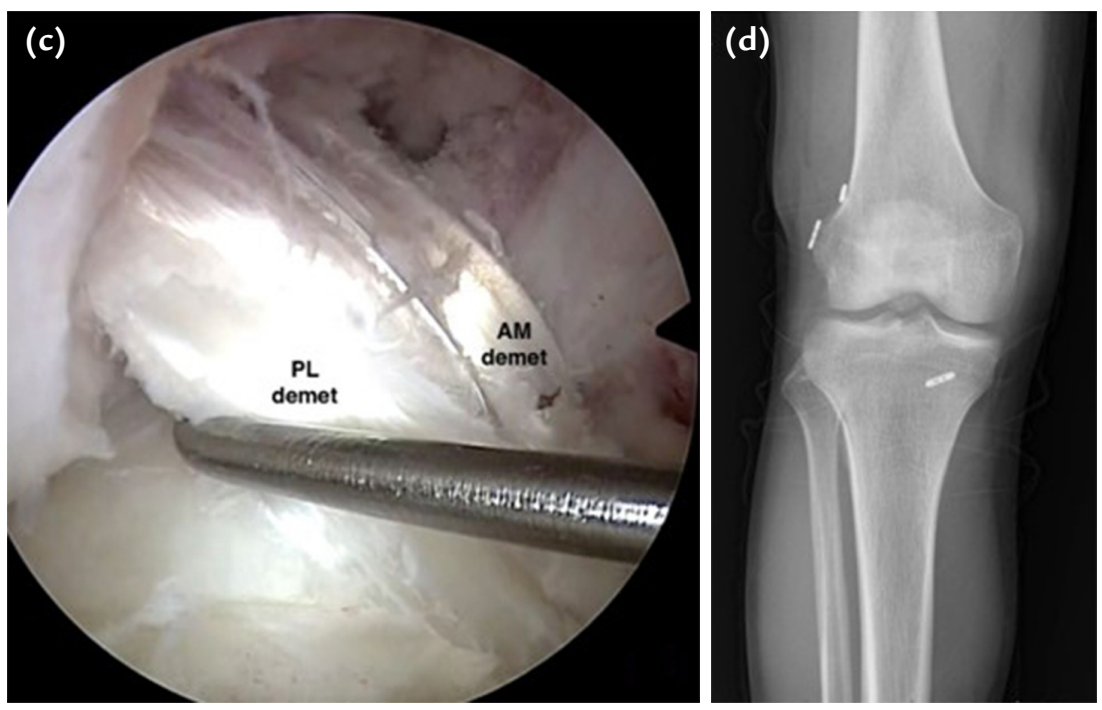

\section{Yazarın Tercih Ettiği Cerrahi Teknik: "Trilink" Çift Demet Tamamı İçeride ÖÇB Rekonstrüksiyonu}

Cerrahiye klasik ÖÇB cerrahisi hazırlı̆̆ı ve pozisyonunda başlanır. Sıklıkla greftin semitendinosus tendonundan, tibial tarafta 8,5-9 mm kalınlığı bulan dörde katlanmış haliyle ve femoral tarafta 5,5-6 mm'yi bulan anteromedial (AM) ve posterolateral (PL) demet kaIınlıklarıyla hazırlanması yeterli olmaktadır. Özellikle erkek hastalarda eğer semitendinöz greft kalınlığı tibial tarafta $8 \mathrm{~mm}$ altında kalırsa greft grasilis tendonuyla desteklenmektedir. AM demet PL demete göre $0,5 \mathrm{~cm}$ uzun olacak şekilde greft hazırlığı yapılmaktadır (Şekil 3a). Femoral tünellerin açılması sırasında Flipcutter (Arthrex, Naples, FL, USA) kullanmadığımızdan uzak anteromedial portalden yapılacak tünel açma işlemlerin tamamında (kılavuz tel uygulaması ve oyma işlemlerinde) medial femoral kondil kıkırdağının korunduğundan emin olarak ilerliyoruz. Öncelikle femoral kılavuz kullanılarak diz hiperfleksiyonda AM tünel açılmakta ve takiben yine femoral kılavuz AM tünele konmak suretiyle (her iki tünel birleşmesine izin vermeyecek ve diverjan olacak şekilde) PL tünel açılır (Şekil 3b, c). Hastanın anatomisine göre değişmekle birlikte AM tünel sıklıkla 25-30 mm olarak, PL tünel ise ortalama $20-25 \mathrm{~mm}$ olarak açılır. Sonrasında taşıyıcı sütürler tünellere yerleştirilir (Şekil 3b). Sonrasında tibial tünel Flipcutter yardımıyla açlır ve taşıyıcı sütür tünele yerleştirilir. Tibial tünel ortalama 25-30 mm olarak açılır. Çift demet uygulamalarında soket uzunluklarının hesaplama sırasında, greftlerin gerdirme tarafi femoral taraf olacak şekilde sokette bırakılması planlanan greft uzunluğundan 5 'er $\mathrm{mm}$ 

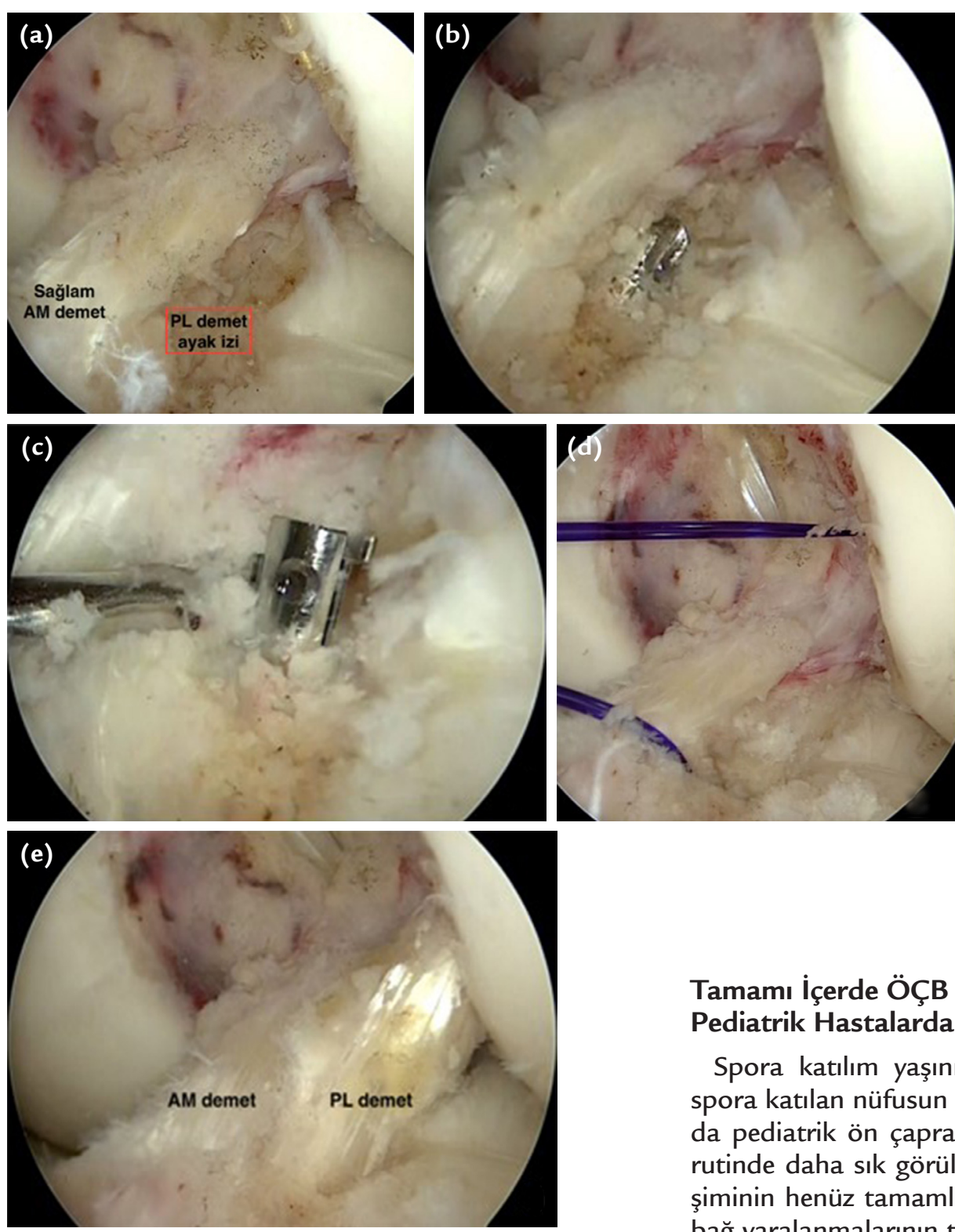

fazla uzunlukta femoral tünel açılması ve tibial soketin içeride kalacak greft uzunluğu kadar açılması pratik olacaktır. Sonrasında uygun şekilde hazırlanmış grefti AM portalden önce tibial taraf press-fit'e yakın oturtularak, sonrada AM ve PL demet sırayla eklem içine yerleştirilir. Bu işlemler sırasında askı sistemlerinin karışmaması için ip sistemleri kullanılabilir. Greft eklem içine yerleştirildikten sonra AM demet 30 derece fleksiyonda, PL demet tam ekstansiyonda gerdirilir. Siklik haraketlerle diz fleksiyona ve ekstansiyona alınarak greft tekrar uygun pozisyonda gerdirilir (Şekil 3d). Sadece demetlerden birinin hasar gördügü olgularda diğer demet korunarak tek demet tamiri (AM veya PL) yapılabilir (Şekil 4).
Şekil 4. a-e. Parsiyel ÖÇB rekonstrüksiyonu (PL demet) uygulanacak hastanın uygun hazırlık yapıldıktan sonraki görünümü (a). Flipcutter yardımıyla tibial tünel açılması (b). Flipcutter kanatları açıldıktan sonra AM demetin bir enstrümanla korunması (c). Taşıma sütürlerinin yerleştirilmesi (d). Uygun gerilme yapıldıktan sonra ÖÇB görünümü (e).

\section{Tamamı İçerde ÖÇB Rekonstrüksiyonunun Pediatrik Hastalarda Kullanımı}

Spora katılım yaşının düşmesi, çocukluk çağında spora katılan nüfusun artması gibi nedenler sonucunda pediatrik ön çapraz bağ yaralanmaları ortopedik rutinde daha sık görülmeye başlanmıştır. İskelet gelişiminin henüz tamamlanmadığı bu grupta ön çapraz bağ yaralanmalarının tedavisi hala tartışmalı bir konu olarak varlığını devam etmektedir.

Pediatrik ÖÇB yaralanmaları olgularına yakın zamanlara kadar sıklıkla hastanın iskelet gelişimi tamamlandıktan sonra ÖÇB rekonstrüksiyonu yapılmakta idi. Bunun nedeni de standart ÖÇB rekonstrüksiyonu tekniklerinin (transepifiziyel) epifizi zedeleyerek büyüme durmasına, uzunluk farkı gelişmesine ve açısal deformiteye neden olabilmesidir. ${ }^{[35]}$ Ancak bu durumda da mevcut diz instabilitesi, tekrarlayan instabilite ataklarına ve zamanla menisküs yırtıkları ve osteokondral lezyonların oluşmasına neden olmaktadır. ${ }^{[36]}$ Konservatif tedavi edilen veya gecikmiş cerrahi yapılan hastaların erken cerrahi yapılmış hastalara göre daha fazla instabilite/laksite gösterdiği ve yaralanma öncesi seviyelerine dönemedikleri gösterilmiştir. ${ }^{[37]}$ Bu nedenlerden dolayı pediatrik ÖÇB yaralanmaları için kısmı ya da tam 

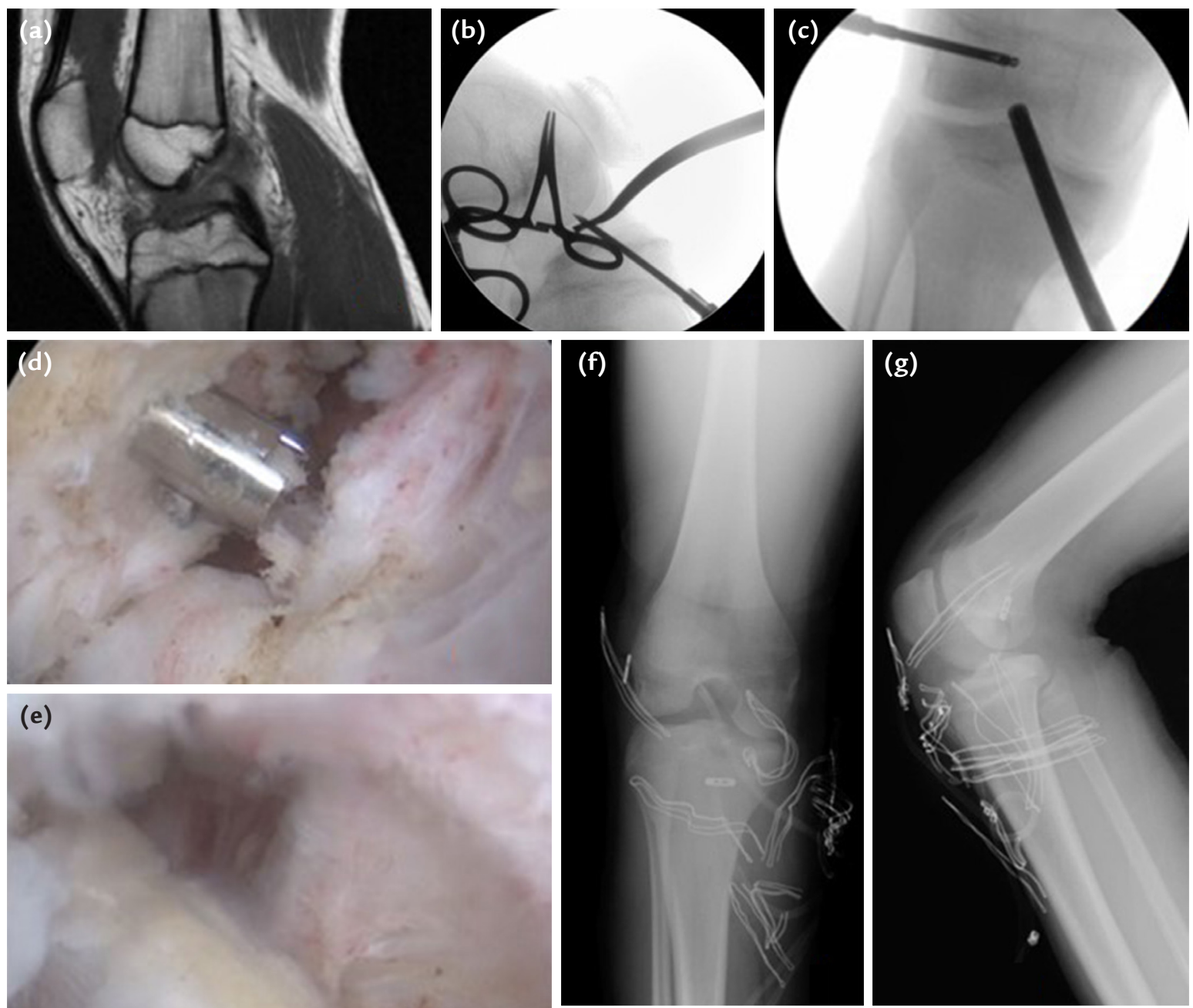

(e)
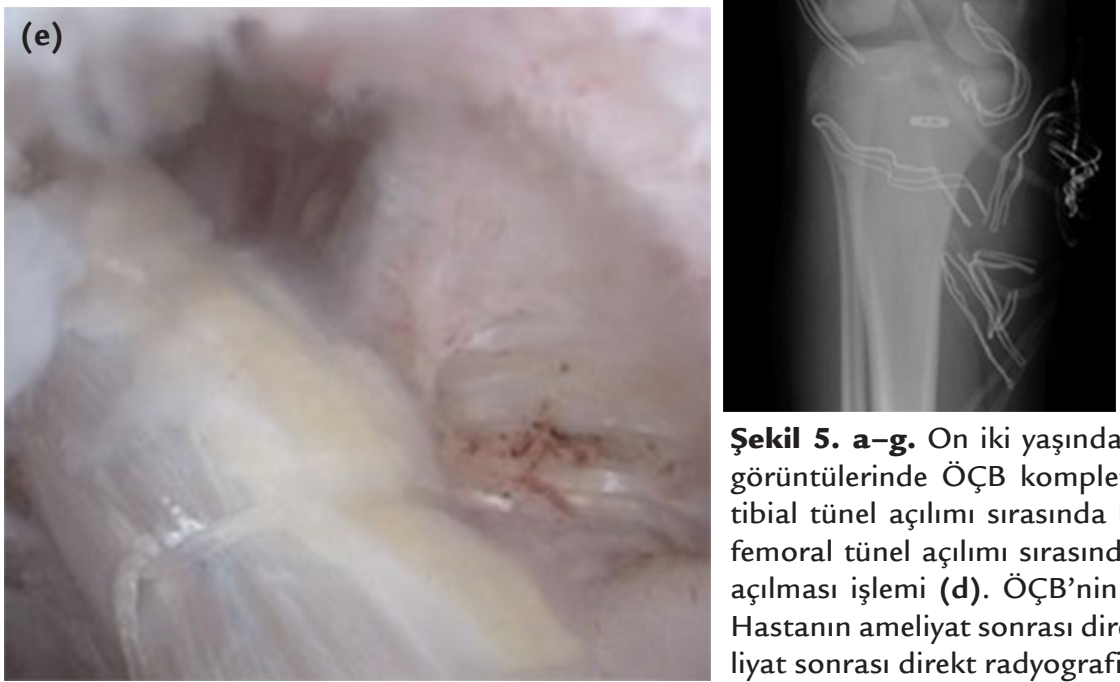

Şekil 5. a-g. On iki yaşında kadın hastanın manyetik rezonans (MR) görüntülerinde ÖÇB komplet rüptüre görünümde (a). Transepifiziyel tibial tünel açılımı sırasında kılavuz tel uygulaması (b). Transepifiziyel femoral tünel açılımı sırasında flipcutter uygulaması (c). Femoral soket açılması işlemi (d). ÖÇB'nin gerdirilmesi sonrasındaki görünümü (e). Hastanın ameliyat sonrası direkt radyografileri (A-P) (f). Hastanın ameliyat sonrası direkt radyografileri (yan) (g).

fizis koruyucu, transfiziyel ve tamamı epifiziyel birçok teknik geliştirilmiştir.

Tamamı içeride - tamamı epifiziyel ÖÇB rekonstrüksiyonu ilk kez McCarthy ve ark. tarafından geliştirildi. Yazarlar tekniklerinin eklem içi anatomiyi diğer fizis koruyucu tekniklere göre daha iyi restore ettiğini ve fizis hasarı riskini minimuma indirdiğini ifade ettiler. ${ }^{[38]}$ Cordasco ve ark., iskelet gelişimini tamamlamamış hastalarda hamstring otogrefti kullanarak yaptıkları tamamı içeride - tamamı epifiziyel ön çapraz bağ rekonstrüksiyonlarında iki yılın sonunda mükemmel klinik ve sonuçlar bildirmişlerdir. ${ }^{[4]}$
Pediatrik ÖÇB yaralanmalarının tedavisinde tamamı epifiziyel yöntemlerin özellikle iki yıl veya daha az kemik gelişimi beklenen olgularda kısmi tamamı içeride parsiyel transfiziyel yöntem kullanılabilir. Bu yöntemde tibial taraf transfiziyel hazırlanırken femoral soket epifiziyel olucak şekilde Flipcutter (Arthrex, Naples, FL, USA) ile açılır. Literatürde her iki yöntemi karşılaştıran çalışmalardan biri Nawabi ve ark.'nın çalışmasıdır. ${ }^{[39]}$ Çalışmada yazarlar hem tamamı epifiziyel (TE) (Şekil 5) hem de kısmi transfiziyel (KTF) tamamı içeride teknik (Şekil 6) uygulamaları sonrası, gelişimi devam eden olgularda fizis anatomisini MR görüntüleme ile 

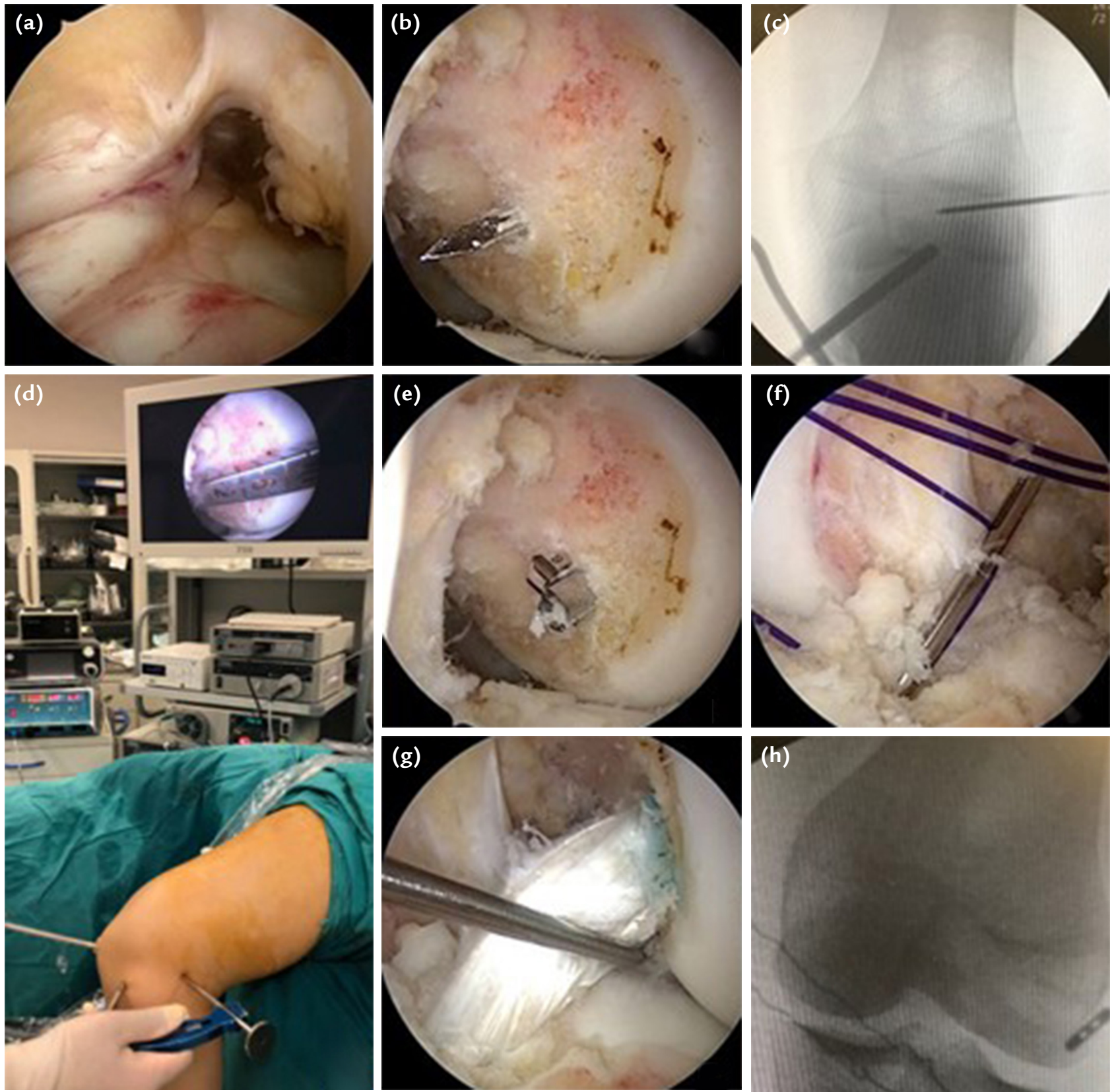

Şekil 6. a-h. On dört yaşında kadın hastanın artroskopik görünümünde tam kat ÖÇB yaralanması görünmekte (a). Hastanın uygun temizlik yapıldıktan sonra femoral kılavuz yardımıyla kılavuz tel gönderilmesi (b). Kılavuz telin skopi ile kontrolü (c). Kılavuz tel ve flipcutter uygulaması sırasında femoral kılavuz kullanımı (d). Flipcutter ile oyma işlemi (e). Taşıma sütürlerinin geçirilmesi (f). ÖÇB tansiyonu sağlandıktan sonra görünüm (g). Hastanın intraoperatif skopi görünümü (h). 
değerlendirmişlerdir. Her iki grupta da femoral soket femoral kılavuz yardımıyla tamamı epizfiziyel olarak retrodrill yöntemiyle açılmıştır. Tibial tarafta transfiziyel soket oluşturdukları olgularda da TE yöntemle soket oluşturdukları olgularda da fizis arresti ile karşılaşmamışlardır. Her ne kadar transfiziyel tibial soket açılan hastalarda fizis hasarı $(\% 5,4)$ kabul edilebilir limitler (toplam fizisin \%4'ü) üzerinde kalsa da, yazarlar bu hastalarda fizis arrestinin olmamasını, hastaların kemik gelişimi tamamlanmasına iki yıldan az kalmış olanlardan seçilmesine bağlamışlardır. Yazarlar ayrıca TE soket açtıkları olgularda da femoral tarafta fizisin total volumünün $\% 1,5^{\prime} \mathrm{i}$, tibial tarafta fizisin total volümünün $\% 2,1$ ' $i$ kadar alanda hasar olduğunu göstermişlerdir. Tibial taraftaki hasar sıklıkla fizisin anteromedialine tekabül ettiği gösterilmiştir. Bizim görüşümüz TE yöntemde tibial soketin ÖÇB ayak izine uygun anatomik planda açma çabası ve fiziste iyatrojenik kırık oluşturmama çabası drillemenin fizisin anteromediale çok yakın olmasına neden olmakta ve bu durum da tibial fizisin anteromedialinde az da olsa hasara neden olmaktadır (Şekil 5b).

\section{Tamamı İçeride Ön Çapraz Bağ Cerrahisi Sonrasında Fizik Tedavi}

Rehabilitasyon klasik ÖÇB cerrahisinden farklı olmamakla birlikte hastaların erken dönemde yük vermesine izin verilmekte ve ağrı eşiklerine göre 1-3 hafta bir çift koltuk değneği kullanmaları önerilmektedir. Terminal zorlayıcı hiperekstansiyon harici diz rom egzersizlerinde herhangi bir kısıtlamaya gidilmemektedir. Erken dönemde (3. hafta) kapalı zincir egzersizlerine başlanmakta, açık zincir egzersizlerine 3. ayda başlanmaktadır. Yarışmacı spora dönüşe 9. aydan sonra izin verilmektedir.

\section{SONUÇ}

Tıbbın her alanında minimal invaziv cerrahi arayışları, zaten artroskopik yöntemlerle gerçekleştirilen ÖÇB cerrahisinde bile daha minimal yöntemlerin arayışııın devam etmesine neden olmaktadır. Tamamı içeride ÖÇB rekonstrüksiyonu da bu arayışların bir sonucu olup belki de ÖÇB yaralanmalarının tedavisinde önemli bir köşe taşı olacaktır. Tek hamstring tendonuyla istenen kalınlıkta tek ya da çift demet rekonstrüksiyon yapılabilmesi tekniğin önemli bir avantajı olarak gözükmektedir. Tek hamstring tendonunun korunmasının klinik karşılığıyla ilgili tartışmalar devam etse de sonuçta tekniğin bu manada daha fizyolojik olduğu kesindir. Tibial periostun korunması erken dönemde hasta konforunu etkilemekte bu da hastaların erken dönem rehabilitasyonu için önemli bir motivasyon nedeni haline gelmektedir. Çalışmanın yazarlarına göre, bu durum tekniğin önemli bir avantajıdır. Spora her gün daha fazla yönelen toplumlarda revizyon ÖÇB cerrahilerinin giderek yaygınlaşması, bununla birlikte çoklu bağ yaralanmalarında çift demet ön ve arka çapraz bağ cerrahilerinin beraber ve teker teker uygulanması gerekliliği, bu tekniğin sağladığı kemik stoğunun daha iyi korunabilme özelliğini önemini daha da artırmaktadır.

Diğer yandan her ne kadar pediatrik olgularda bir takım anatomik ve nonanatomik rekonstrüksiyon yöntemleri tanımlanmış olsa da tamamı içeride ÖÇB rekonstrüksiyonu tekniğe alışık cerrahlar için uygulama kolaylığı ve fizis arrestini engelleyici içeriden dışarı delme tekniği sayesinde oldukça güvenli, yüz güldürücü sonuçları olan anatomik bir rekonstrüksiyon yöntemi sağlamaktadır.

Güncel literatür tamamı içeride ÖÇB rekonstrüksiyonu cerrahisinin uzun dönem sonuçlarını klasik yöntemle benzer olarak tanımlasa da aynı sonuca daha az kemik ve tendon hasarı ile ulaşılabilmesi bu tekniğin çok önemi bir avantajı olduğunu düşünüyoruz.

\section{KAYNAKLAR}

1. Cerulli G, Zamarra G, Vercillo F, Pelosi F. ACL reconstruction with "the original all-inside technique". Knee Surg Sports Traumatol Arthrosc 2011;19(5):829-31. Crossref

2. de Sa D, Shanmugaraj A, Weidman M, Peterson DC, Simunovic N, Musahl V, Ayeni O. All-Inside Anterior Cruciate Ligament Reconstruction-A Systematic Review of Techniques, Outcomes, and Complications. J Knee Surg 2018;31(9):895904. Crossref

3. Lubowitz JH. No-tunnel anterior cruciate ligament reconstruction: the transtibial all-inside technique. Arthroscopy 2006;22(8):900.e1-11. Crossref

4. Cordasco FA, Mayer SW, Green DW. All-Inside, AllEpiphyseal Anterior Cruciate Ligament Reconstruction in Skeletally Immature Athletes: Return to Sport, Incidence of Second Surgery, and 2-Year Clinical Outcomes. Am J Sports Med 2017;45(4):856-63. Crossref

5. Thaunat M, Clowez G, Murphy CG, Desseaux A, Guimaraes T, Fayard JM, Sonnery-Cottet B, et al. All-Inside Bicruciate Ligament Reconstruction Technique: A Focus on Graft Tensioning Sequence. Arthrosc Tech 2017;6(3):e655-60. Crossref

6. Morgan CD, Kalmam VR, Grawl DM. Isometry testing for anterior cruciate ligament reconstruction revisited. Arthroscopy 1995;11(6):647-59. Crossref

7. Kim SG, Kurosawa H, Sakuraba K, Ikeda H, Takazawa S, Takazawa Y. Development and application of an inside-toout drill bit for anterior cruciate ligament reconstruction. Arthroscopy 2005;21(8):1012.e1-4. Crossref

8. Lubowitz $\mathrm{JH}$, Ahmad CS, Anderson K. All-inside anterior cruciate ligament graft-link technique: second-generation, no-incision anterior cruciate ligament reconstruction. Arthroscopy 2011;27(5):717-27. Crossref

9. Blackman AJ, Stuart MJ. All-inside anterior cruciate ligament reconstruction. J Knee Surg 2014;27(5):347-52. Crossref

10. Benea $\mathrm{H}$, d'Astorg $\mathrm{H}$, Klouche $\mathrm{S}$, Bauer $\mathrm{T}$, Tomoaia $\mathrm{G}$, Hardy $P$. Pain evaluation after all-inside anterior cruciate ligament reconstruction and short term functional results of a prospective randomized study. Knee 2014;21(1):102-6. Crossref 
11. Lubowitz JH, Schwartzberg R, Smith P. Randomized controlled trial comparing all-inside anterior cruciate ligament reconstruction technique with anterior cruciate ligament reconstruction with a full tibial tunnel. Arthroscopy 2013;29(7):1195-200. Crossref

12. Lubowitz JH. All-inside ACL. retroconstruction controversies. Sports Med Arthrosc Rev 2010;18(1):20-6. Crossref

13. Schurz M, Tiefenboeck TM, Winnisch M, Syre S, Plachel F, Steiner G, Hajdu S, Hofbauer M. Clinical and Functional Outcome of All-Inside Anterior Cruciate Ligament Reconstruction at a Minimum of 2 Years' Follow-up. Arthroscopy 2016;32(2):332-7. Crossref

14. McAdams TR, Biswal S, Stevens KJ, Beaulieu CF, Mandelbaum BR. Tibial aperture bone disruption after retrograde versus antegrade tibial tunnel drilling: a cadaveric study. Knee Surg Sports Traumatol Arthrosc 2008;16(9):818-22. Crossref

15. Volpi P, Bait C, Cervellin M, Denti M, Prospero E, Morenghi E, Quaglia A. No difference at two years between all inside transtibial technique and traditional transtibial technique in anterior cruciate ligament reconstruction. Muscles Ligaments Tendons J 2014;4(1):95-9. https://www.ncbi.nlm.nih.gov/ pmc/articles/PMC4049659/

16. Connaughton AJ, Geeslin AG, Uggen CW. All-inside ACL reconstruction: How does it compare to standard $A C L$ reconstruction techniques? J Orthop 2017;14(2):241-6. Crossref

17. Mayr R, Heinrichs $\mathrm{CH}$, Eichinger M, Coppola C, Schmoelz W, Attal R. Biomechanical comparison of 2 anterior cruciate ligament graft preparation techniques for tibial fixation: adjustable-length loop cortical button or interference screw. Am J Sports Med 2015;43(6):1380-5. Crossref

18. Walsh MP, Wijdicks CA, Parker JB, Hapa O, LaPrade RF. A comparison between a retrograde interference screw, suture button, and combined fixation on the tibial side in an all-inside anterior cruciate ligament reconstruction: a biomechanical study in a porcine model. Am J Sports Med 2009;37(1):160-7. Crossref

19. Ilahi OA, Nolla JM, Ho DM. Intra-tunnel fixation versus extra-tunnel fixation of hamstring anterior cruciate ligament reconstruction: a meta-analysis. J Knee Surg 2009;22(2):1209. Crossref

20. Smith PA, Stannard JP, Pfeiffer FM, Kuroki K, Bozynski CC, Cook JL. Suspensory Versus Interference Screw Fixation for Arthroscopic Anterior Cruciate Ligament Reconstruction in a Translational Large-Animal Model. Arthroscopy 2016;32(6):1086-97. Crossref

21. Mayr R, Heinrichs $\mathrm{CH}$, Eichinger M, Smekal V, Schmoelz W, Attal R. Preparation techniques for all-inside ACL cortical button grafts: a biomechanical study. Knee Surg Sports Traumatol Arthrosc 2016;24(9):2983-9. Crossref

22. Barrow AE, Pilia M, Guda T, Kadrmas WR, Burns TC. Femoral suspension devices for anterior cruciate ligament reconstruction: do adjustable loops lengthen? Am J Sports Med 2014;42(2):343-9. Crossref

23. Segawa $H$, Omori G, Koga $Y$, Kameo $T$, lida S, Tanaka M. Rotational muscle strength of the limb after anterior cruciate ligament reconstruction using semitendinosus and gracilis tendon. Arthroscopy 2002;18(2):177-82. Crossref

24. Monaco E, Redler A, Fabbri M, Proietti L, Gaj E, Daggett $M$, Ferretti $A$. Isokinetic flexion strength recovery after $A C L$ reconstruction: a comparison between all inside graft-link technique and full tibial tunnel technique. Phys Sportsmed 2019;47(1):132-5. Crossref

25. Cournapeau J, Klouche S, Hardy P. Material costs of anterior cruciate ligament reconstruction with hamstring tendons by two different techniques. Orthop Traumatol Surg Res 2013;99(2):196-201. Crossref
26. Georgoulis AD, Pappa L, Moebius $U$, Malamou-Mitsi $V$, Pappa S, Papageorgiou CO, Agnantis NJ, Soucacos PN. The presence of proprioceptive mechanoreceptors in the remnants of the ruptured $A C L$ as a possible source of re-innervation of the ACL autograft. Knee Surg Sports Traumatol Arthrosc 2001;9(6):364-8. Crossref

27. Gohil S, Annear PO, Breidahl W. Anterior cruciate ligament reconstruction using autologous double hamstrings: a comparison of standard versus minimal debridement techniques using $\mathrm{MRI}$ to assess revascularisation. A randomised prospective study with a one-year follow-up. J Bone Joint Surg Br 2007;89-B(9):1165-71. Crossref

28. Hong L, Li X, Zhang $H$, Liu X, Zhang J, Shen JW, Feng $H$. Anterior cruciate ligament reconstruction with remnant preservation: a prospective, randomized controlled study. Am J Sports Med 2012;40(12):2747-55. Crossref

29. Kosy JD, Mandalia VI. Anterior cruciate ligament mechanoreceptors and their potential importance in remnant-preserving reconstruction: a review of basic science and clinical findings. J Knee Surg 2018;31(8):736-46. Crossref

30. Smith PA, Schwartzberg RS, Lubowitz JH. No tunnel 2-socket technique: all-inside anterior cruciate ligament doublebundle retroconstruction. Arthroscopy 2008;24(10):1184-9. Crossref

31. Tsai AG, Wijdicks CA, Walsh MP, Laprade RF. Comparative kinematic evaluation of all-inside single-bundle and double-bundle anterior cruciate ligament reconstruction: a biomechanical study. Am J Sports Med 2010;38(2):263-72. Crossref

32. Yasen SK, Logan JS, Smith JO, Nancoo T, Risebury MJ, Wilson AJ. TriLink: Anatomic Double-Bundle Anterior Cruciate Ligament Reconstruction. Arthrosc Tech 2014;3(1):e13-20. Crossref

33. Watanabe S, Takahashi T, Hino K, Kutsuna T, Ohnishi Y, Ishimaru M, Miura H. Short-Term Study of the Outcome of a New Instrument for All-Inside Double-Bundle Anterior Cruciate Ligament Reconstruction. Arthroscopy 2015;31(10):1893-902. Crossref

34. Takahashi T, Watanabe S, Miura H. All-Inside Double-Bundle Anterior Cruciate Ligament Reconstruction via the Transtibial Approach With a Laser-Tip Guide System for Drilling. Arthrosc Tech 2019;8(7):e755-62. Crossref

35. Chudik S, Beasley L, Potter H, Wickiewicz T, Warren R, Rodeo $\mathrm{S}$. The influence of femoral technique for graft placement on anterior cruciate ligament reconstruction using a skeletally immature canine model with a rapidly growing physis. Arthroscopy 2007;23(12):1309-19.e1. Crossref

36. Werner BC, Yang S, Looney AM, Gwathmey FW Jr. Trends in Pediatric and Adolescent Anterior Cruciate Ligament Injury and Reconstruction. J Pediatr Orthop 2016;36(5):447-52. Crossref

37. Ramski DE, Kanj WW, Franklin CC, Baldwin KD, Ganley TJ. Anterior cruciate ligament tears in children and adolescents: a meta-analysis of nonoperative versus operative treatment. Am J Sports Med 2014;42(11):2769-76. Crossref

38. McCarthy MM, Graziano J, Green DW, Cordasco FA. Allepiphyseal, all-inside anterior cruciate ligament reconstruction technique for skeletally immature patients. Arthrosc Tech 2012;1(2):e231-9. Crossref

39. Nawabi DH, Jones KJ, Lurie B, Potter HG, Green DW, Cordasco FA. All-inside, physeal-sparing anterior cruciate ligament reconstruction does not significantly compromise the physis in skeletally immature athletes: a postoperative physeal magnetic resonance imaging analysis. Am J Sports Med 2014;42(12):2933-40. Crossref 